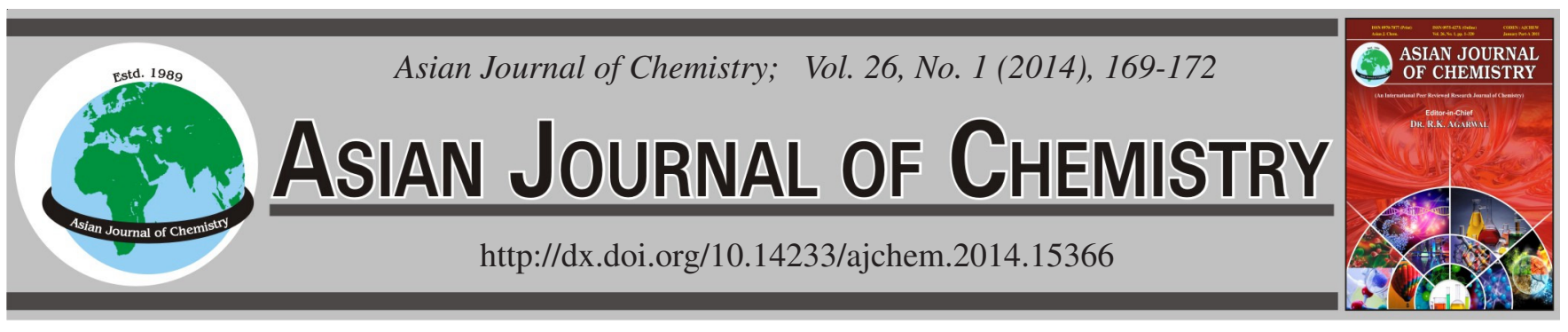

\title{
Ultrasonic-Assisted Dispersive Liquid Phase Microextration with Low-Volume Toxic Solvent for the Separation of Strontium and its Application for Strontium Isotope Determination
}

\author{
Aide Sun ${ }^{1}$, Qingcai Xu ${ }^{1}$, Shujian Xu ${ }^{1}$, Xuehui ShangGuan ${ }^{1}$ and Jing Sun ${ }^{2, *}$
}

${ }^{1}$ Shandong Provincial Key Laboratory of Soil Conservation and Environmental Protection, College of Resource and Environment, Linyi University, Linyi 276005, Shandong Province, P.R. China

${ }^{2}$ Qinghai Key Laboratory of Qinghai-Tibet Plateau Biological Resources, Northwest Institute of Plateau Biology, Chinese Academy of Sciences, 23 Xinning Road, Chengxi District, Xining 810008, P.R. China

*Corresponding author: Fax: +86 971 6143282; Tel: +86 971 6143898; E-mail: sunj@nwipb.cas.cn

\begin{abstract}
In this paper, a new and novel method of ultrasonic-assisted dispersive liquid phase microextration was applied for the pre-concentration of trace strontium ion in water samples, which was determined by inductively coupled plasma optical emission spectroscopy. In this pretreatment, acetonitrile was used as dispersive solvent, 1,1,2,2-tetrachloroethane as an extractant and dicyclohexyl-18-crown-6 as the chelating reagent. The factors influencing the extraction of the method were optimized. These factors were type and volume of extraction solvents, the type and volume of dispersive solvents, $\mathrm{pH}$ value and extraction time. The linear ranged from 40 to $2000 \mu \mathrm{g} / \mathrm{L}$ with the limit of detection of $12 \mu \mathrm{g} / \mathrm{L}$. Under the optimum condition, the amount of strontium and the variation of strontium isotopic composition in four real water samples were investigated by the proposed method. The method can be applied to the determination of strontium and its isotopic composition in environmental samples.
\end{abstract}

Keywords: Isotopic composition, Strontium, Ultrasonic-assisted dispersive liquid phase microextration, Water.

\section{INTRODUCTION}

It is well known that strontium and its isotopic composition are always as useful tools applied in the fields of archaeology ${ }^{1-3}$, the water-rock interaction ${ }^{4,5}$, stratigraphic geology ${ }^{6}$ for the identification of origin ${ }^{7}$ and the evolution of environment and climate. In these fields, the precision of strontium ion concentration, especially its isotope composition, almost depended on the pre-concentration and purification of strontium ion from environmental samples. So an efficient extraction for strontium ion can obtain the authentic and accurate results that veritably retained the information of the environment and evolution at that time.

The separation for strontium ion includes anion ion exchange resin ${ }^{8,9}$, Sr-specific resin ${ }^{10}$, liquid-liquid microextraction ${ }^{11}$. Valentová et al. ${ }^{12}$ and Nový et al. ${ }^{13}$ theoretically reported the mechanism of the dicyclohexyl 18-crown-6 as chelating ligand bonding with strontium ion. Fan et al. ${ }^{11}$ briefly described the extraction of strontium ion in water samples, in which dicyclohexyl 18-crown-6 was used as the chelating ligand. But the various factors influencing the extraction efficiency of strontium ion were not discussed.

The reported method is based on the use of liquid-liquid microextraction in a ternary system named dispersive liquid- liquid microextraction for strontium ion. The determination of strontium ion was performed using ICP-OES. The factors influencing the efficiency and pre-concentration capability of the method were investigated. The method with high detection limit and confidence level can lead to an easy determination of trace amounts of strontium ion and can be applied in the determination of strontium isotope.

\section{EXPERIMENTAL}

The standard solution of strontium $(100 \mu \mathrm{g} / \mathrm{mL})$ was purchased from the National Research Center for Certified Reference Materials in China (Beijing, China). 1,1,2,2-Tetrachloroethane, chloroform, tetrachloromethane, methanol, acetonitrile, acetone were of HPLC reagents. Nitric acid was of guarantee reagent. Dicyclohexyl-18-crown-6 $\left(\mathrm{DC}_{18} \mathrm{C}_{6}\right)$ was Standard reagent. Deionized water was used for the preparation of working and standard solution.

A simultaneous inductively coupled plasma optical emission spectrography (ICP-OES, Vista MPX, Varian, USA,) with $40 \mathrm{MHz}$ RF generator and a charge coupled device detector (Vista Chip) was used for the determination of strontium ion. The spectrography was operated in the transient signal acquisition mode. 
A GV multiple-collector inductively couples plasma mass spectrometer (MC-ICP-MS) was applied to determine the composition of strontium isotope, which has a magnetic sector detection (IsoProbe, UK), equipped with a Meinhard PFA nebulizer, a multiple-collector system with nine Faraday cups, four ion-counters and one Daly detector.

Ultrasonic-assisted dispersive liquid phase microextration: A $5 \mathrm{~mL}$ water sample was placed in a $10 \mathrm{~mL}$ polypropylene test tube with a conical bottom and spiked with $400 \mu \mathrm{g} / \mathrm{L}$ standard strontium(II) solution. The $\mathrm{pH}$ of the solution was adjusted to 4.5 with nitric acid. After the addition of $0.5 \mathrm{~mL}$ of $0.1356 \mathrm{mmol} / \mathrm{L} \mathrm{DC}{ }_{18} \mathrm{C}_{6}$ as chelating agent, $0.5 \mathrm{~mL}$ of acetonitrile as dispersive solvent and $150 \mu \mathrm{L}$ of 1,1,2,2tetrachloroethane as the extractant were rapidly injected into the solution. The mixed solution was vibrated by the ultrasonic probe at $100 \mathrm{~W}$ ultrasonic bath at $35 \pm 2{ }^{\circ} \mathrm{C}$. A cloudy mixture was formed in the test tube for $20 \mathrm{~min}$. Then, the mixture was centrifuged at $5000 \mathrm{rpm}$ for $3 \mathrm{~min}$ for phase separation. Thus, the organic phase was sedimented at the conical bottom of the test tube. A $100 \mu \mathrm{L}$ microsyringe was used to transfer the organic phase to a test tube. After the evaporation of the organic solvent at room temperature with nitrogen purge, $0.5 \mathrm{~mL}$ of $3 \%$ of nitric acid was added and strontium(II) in this solution was determined by ICP-OES and for analysis of strontium isotope.

Water samples: Four local environment water samples, wastewater, river water, tap water and underground water, were collected and used for the validation of the proposed method. Wastewater was collected from a wastewater pretreatment plant, Linyi city (Shandong Province, China). River water sample was from local river. Underground water sample was collected in the well. Tap water sample was from our laboratory. All the samples were filtered through $0.45 \mu \mathrm{m}$ mocro-pore membranes and stored at low temperature for the subsequent test.

\section{RESULTS AND DISCUSSION}

In this study, dispersive liquid phase microextraction (DLPME) was applied for the extraction of strontium(II) from the aqueous phase into the organic phase. In order to gain the best extraction performance of strontium(II), type and volume of extractant, type and volume of dispersive solvent, extraction time, $\mathrm{pH}$ were optimized. The designed experiments were investigated.

Effect of type and volume of extractants: The selection of a proper extraction solvent is very essential for the DLPME method, which is closely related to the chemical nature of the chelating reagent. The extraction solvent with good extraction properties and low water solubility should have higher density than water ${ }^{14}$. What's more, with the addition of extraction solvent based on ultrasonic assisted microextraction, a cloudy solution can be formed easily in the aqueous solution ${ }^{15,16}$. Three different extracting solvents i.e., chloroform, tetrachloromethane and 1,1,2,2-tetrachloroethane were taken into condition for the extraction of $\mathrm{Sr}$ (II). The results (Fig. 1) indicated that 1,1,2,2tetrachloroethane as an extraction solvent in the UA-DLPME procedure can achieve more excellent enrichment and isolation of strontium(II) from aqueous phase than that two extraction

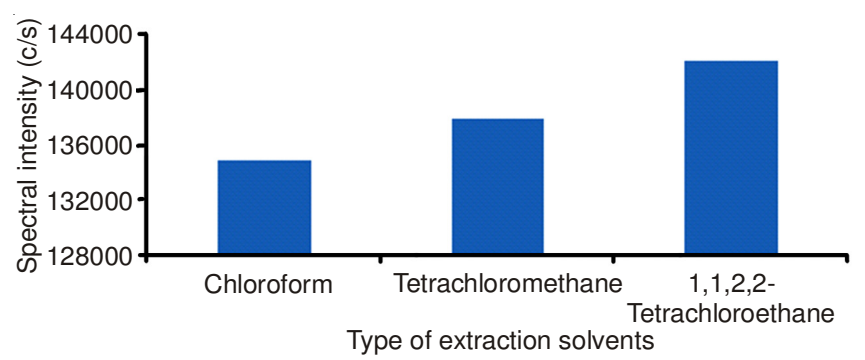

Fig. 1. Effect of the type of extraction solvent on the extraction efficiency of strontium. Extraction condition: sample volume $5 \mathrm{~mL}$, spiked concentration $400 \mu \mathrm{g} \mathrm{L}$, olume of dispersive solvent $0.5 \mathrm{~mL}, \mathrm{pH}$ 4.5 , extraction time $20 \mathrm{~min}$

solvents, chloroform and tetrachloromethane. So 1,1,2,2-tetrachloroethane was chosen as the extraction solvent in further works.

Volume of extraction solvent: Another crucial factor, volume of extraction solvent (1,1,2,2-tetrachloroethane), also influences the extraction efficiency of UA-DLPME. The volume of 1,1,2,2-tetrachloroethane ranging from 50 to $300 \mu \mathrm{L}$ was considered in the experiment design. The change of extraction efficiency with different volume of extractant is shown in Fig. 2. Fig. 2 showed that with the volume increasing of 1,1,2,2-tetrachloroethane between 50-150 $\mu \mathrm{L}$, extraction efficiency of strontium(II) increased. When the volume of extractant is more than $150 \mu \mathrm{L}$, the changes in the extraction efficiency of $\mathrm{Sr}(\mathrm{II})$ has become stable. Therefore, $150 \mu \mathrm{L}$ 1,1,2,2-tetrachloroethane was applied in subsequent experiments.

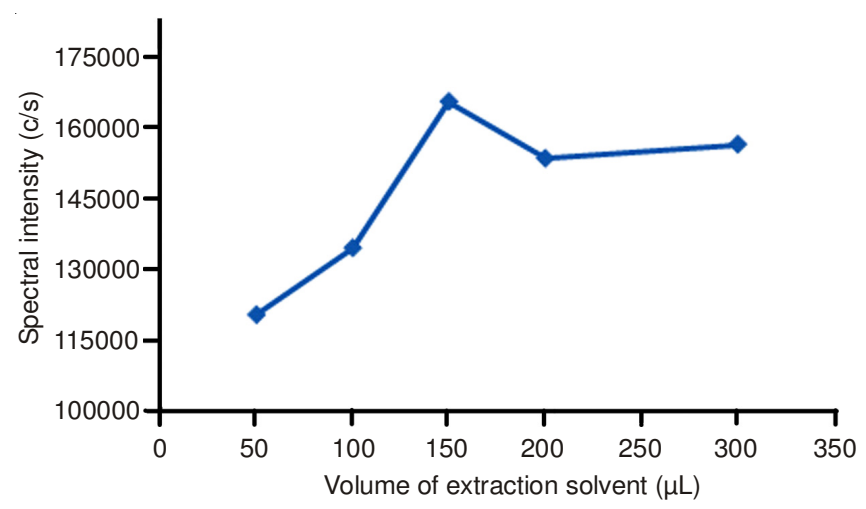

Fig. 2. Effect of volume of extraction solvent on the extraction efficiency of strontrium. Extraction condition: sample volume $5 \mathrm{~mL}$, spiked concentration $400 \mu \mathrm{g} / \mathrm{L}$, volume of dispersive solvent $0.5 \mathrm{~mL}, \mathrm{pH}$ 4.5 , extraction time $20 \mathrm{~min}$

Effect of type and volume of dispersive solvent: With the consideration of the miscibility of dispersive solvent between extraction solvent and aqueous phase, three solvents, acetone, methanol and acetonitrile were used as dispersive solvent for tests. $0.5 \mathrm{~mL}$ each dispersive solvent containing $150 \mu \mathrm{L}$ 1,1,2,2-tetrachloroethane was used in the experiments. The results (Fig. 3) demonstrated that acetonitrile as dispersive solvent has higher enrichment factor than the others. Acetonitrile was chosen as dispersive solvent for the highest extraction efficiency.

The effect on the efficiency of the extraction of $\mathrm{Sr}$ (II) affected by the volume of dispersive solvent acetonitrile was 


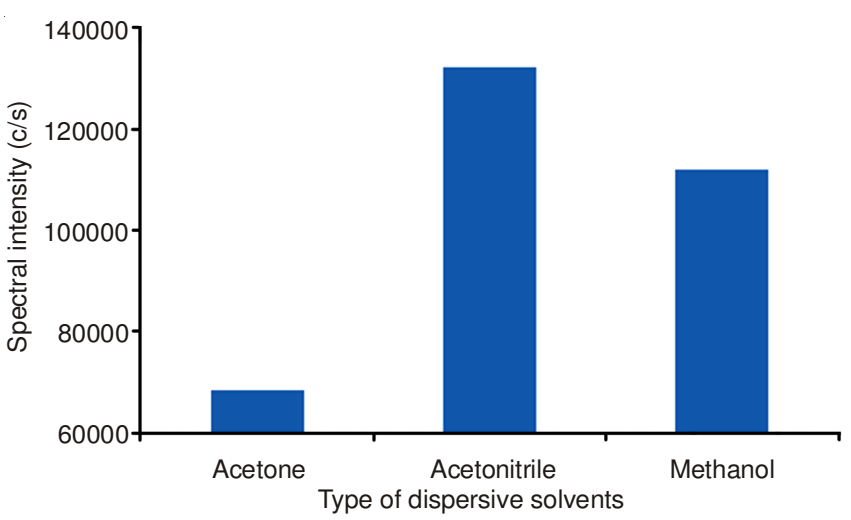

Fig. 3. Effect of type of dispersive solvent on the extraction efficiency of strontrium. Extraction condition: sample volume $5 \mathrm{~mL}$, spiked concentration $400 \mu \mathrm{g} / \mathrm{L}$, volume of extraction solvent $150 \mu \mathrm{L}, \mathrm{pH}$ 4.5 , extraction time $20 \mathrm{~min}$

investigated. The experimental results illustrated in Fig. 4, indicated that at the beginning, with the increasing of the volume of acetonitrile, the efficiency of extraction for $\mathrm{Sr}$ (II) increased. When the volume of dispersive solvent acetonitrile was $0.5 \mathrm{~mL}$, the efficiency reached the maximum. It may be caused by the reason that at low volume of acetonitrile, the cloudy point is not formed well with low enrichment factor. With more addition of acetonitrile, there is more $\mathrm{Sr}$ (II) chelate dissolved in the water. Thus, the extraction efficiency decreases. When the volume of acetonitrile was more than $1.5 \mathrm{~mL}$, the cloudy state of the solution disappeared. Therefore, $0.5 \mathrm{~mL}$ of acetonitrile was used as dispersive solvent in the following tests.

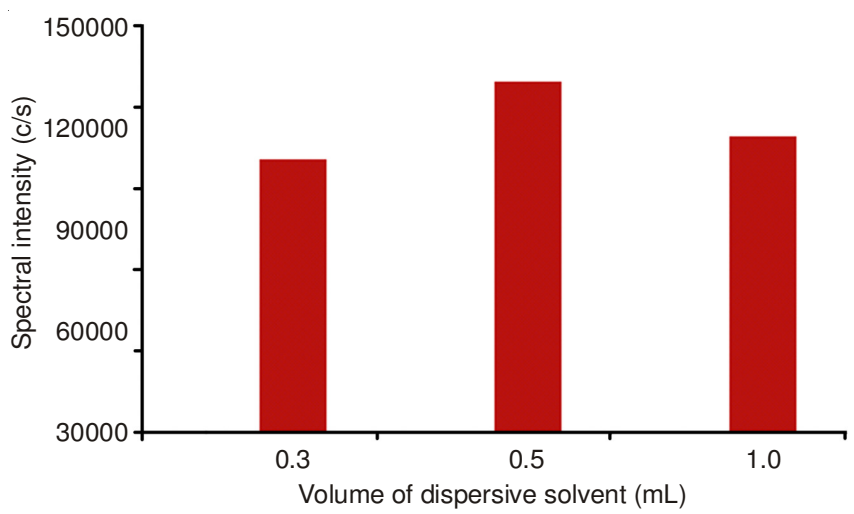

Fig. 4. Effect of volume of dispersive solvent on the extraction efficiency of strontrium. Extraction condition: sample volume $5 \mathrm{~mL}$, spiked concentration $400 \mu \mathrm{g} / \mathrm{L}$, volume of extraction solvent $150 \mu / \mathrm{L}$, volume of dispersive solvent $0.5 \mathrm{~mL}, \mathrm{pH} 4.5$, extraction time 20 $\min$

Effect of extraction time: Extraction time is a critical factor that can affect the efficiency of target compounds transferring from the aqueous phase into the extractant. Extraction time ranging from 5 to $40 \mathrm{~min}$ were investigated with other experiment conditions holding at their optimum. The results showed that with the increase of extraction time over $20 \mathrm{~min}$, the spectra intensity remain constant. This may be because the formation of cloudy solution makes the surface area between extractant and the aqueous phase large infinitely, so target compound transfers rapidly from aqueous phase into extractant and the equilibrium is achieved (Fig. 5).

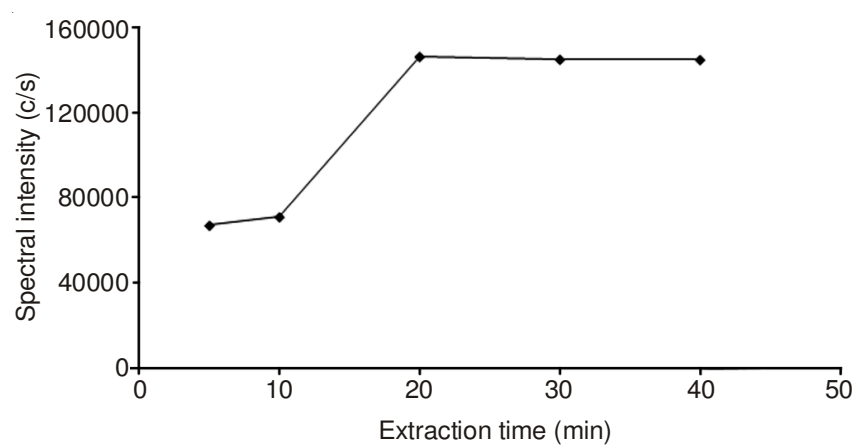

Fig. 5. Effect of extraction time on the extraction efficiency of strontrium. Extraction condition: sample volume $5 \mathrm{~mL}$, spiked concentration $400 \mu \mathrm{g} / \mathrm{L}$, volume of extraction solvent $150 \mu \mathrm{L}$, volume of dispersive solvent $0.5 \mathrm{~mL}, \mathrm{pH} 4.5$

Effect of pH: $\mathrm{pH}$ is an important factor for the quantitative recovery of metal ions because the complex formation of metal ions and hydrolysis of cations depended on the $\mathrm{pH}$ of the aqueous solution. The influence of $\mathrm{pH}$ in the range of 3-7, was investigated in a series of experiments. $\mathrm{pH}$ was adjusted by nitric acid or sodium hydroxide solution. The results are shown in Fig. 6. As can be seen from Fig. 6, maximum extraction of $\mathrm{Sr}$ (II) was obtained at the $\mathrm{pH}$ value of 4-5. Low extraction occurs in the lower $\mathrm{pH}$ are probably due to the protonation of chelate, which can reduce the ability of chelate group bind with strontium ion. Thus, $\mathrm{pH}$ at 4.5 was chosen for further studies.

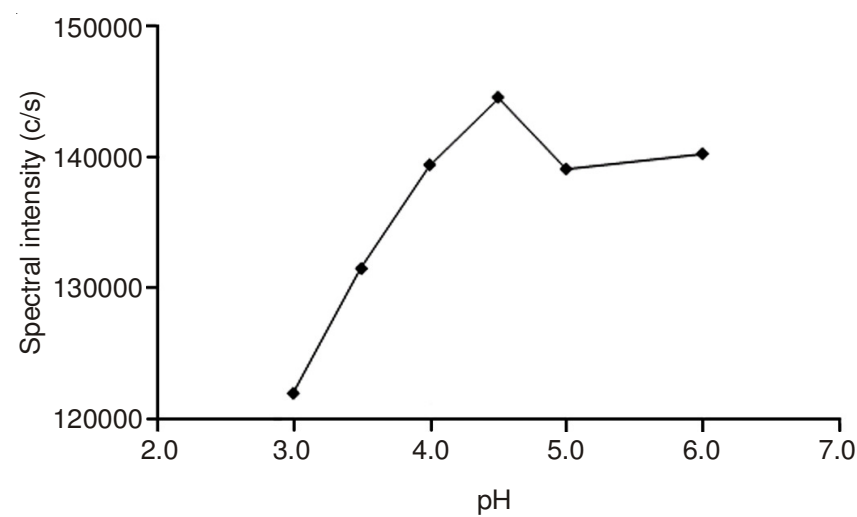

Fig. 6. Effect of $\mathrm{pH}$ on the extraction efficiency of strontrium. Extraction condition: sample volume $5 \mathrm{~mL}$, spiked concentration $400 \mu \mathrm{g} / \mathrm{L}$, volume of extraction solvent $150 \mu \mathrm{L}$, volume of dispersive solvent $0.5 \mathrm{~mL}$, extraction time $20 \mathrm{~min}$

Interference study: The influence of foreign ions which interferred with the determination of target ion by the present method was investigated.

$5 \mathrm{~mL}$ of solution with $400 \mu \mathrm{g} / \mathrm{L} \mathrm{Sr}(\mathrm{II})$ and other ions were tested in dispersive liquid phase microextraction. The results are shown in Table-1. It is obvious that the most of the foreign ions did not affect the extraction of $\mathrm{Sr}$ (II).

Analytical performance: Under the optimum experimental conditions, the analytical characteristics such as linear range, correlation coefficient and limit of detection were examined, which were listed in Table-2. The linear range was between 40-2000 $\mu \mathrm{g} / \mathrm{L}$ with UA-DLPME pre-concentration and $200-5000 \mu \mathrm{g} / \mathrm{L}$ without UA-DLPME. The limit of detection is 12 for UA-DLPME with $5.4 \%$ of RSD and 38 without UADMPLE with $4.0 \%$ of RSD. 


\begin{tabular}{cc}
\hline \multicolumn{2}{c}{ TABLE-1 } \\
EFFECT OF INTERFERENCE IONS \\
ON THE EXTRACTION OF Sr(II) \\
\hline Coexisting ions & Amount of interference ions (mg/L) \\
\hline $\mathrm{NO}_{3}^{-}$ & 3000 \\
$\mathrm{Cl}^{-}$ & 2000 \\
$\mathrm{Mg}^{2+}, \mathrm{Ca}^{2+}, \mathrm{Ba}^{2+}$ & 100 \\
$\mathrm{Na}^{+}, \mathrm{K}^{+}, \mathrm{Li}^{+}$ & 50 \\
$\mathrm{Cr}^{3+}, \mathrm{Cu}^{2+}, \mathrm{Fe}^{2+}, \mathrm{Fe}^{3+}$ & 650 \\
$\mathrm{Ni}^{2+}, \mathrm{Mn}^{2+}, \mathrm{Co}^{2+}$ & 800 \\
$\mathrm{SO}_{4}^{2-}$ & 100 \\
\hline
\end{tabular}

\begin{tabular}{|c|c|c|}
\hline \multicolumn{3}{|c|}{$\begin{array}{c}\text { TABLE-2 } \\
\text { LINEAR RANGE, LIMIT OF DETECTION } \\
\text { AND REPEATABILITY OF THE METHOD }\end{array}$} \\
\hline Analytical parameters & $\begin{array}{l}\text { With UA-DLPME } \\
\text { pre-concentration }\end{array}$ & $\begin{array}{c}\text { Without } \\
\text { UA-DLPME }\end{array}$ \\
\hline Linear range $(\mu \mathrm{g} / \mathrm{L})$ & $40-2000$ & $200-5000$ \\
\hline $\mathrm{R}$ & 0.9987 & 0.999 \\
\hline Limit of detection $(\mu \mathrm{g} / \mathrm{L})$ & 12 & 38 \\
\hline $\operatorname{RSD}(\%)$ & 5.4 & 4.0 \\
\hline
\end{tabular}

Analysis of real water samples: Three real environmental water samples were used to assess the applicability of the proposed method. The experimental results (Table-3) indicated that in all these cases, the recoveries of $\mathrm{Sr}$ (II) in water samples can be quantitative.

\begin{tabular}{lccc}
\multicolumn{4}{c}{ TABLE-3 } \\
\multicolumn{4}{c}{ EXPERIMENTAL RECOVERIES OF } \\
Sr(II) FROM REAL WATER SAMPLES \\
\hline \multicolumn{1}{c}{ Water samples } & $\begin{array}{c}\text { Conc. } \\
(\mu \mathrm{g} / \mathrm{L})\end{array}$ & $\begin{array}{c}\text { Added amount } \\
(\mu \mathrm{g} / \mathrm{L})\end{array}$ & Recoveries $(\%)$ \\
\hline Tap water & 47.4 & 100 & 98.3 \\
River water & 132.5 & 100 & 104.2 \\
Wastewater & 201.4 & 100 & 99.7 \\
Underground water & 88.6 & 100 & 100.8 \\
\hline
\end{tabular}

Measurement of strontium isotopic composition: The isotopic composition for $\mathrm{Sr}$ was calculated to make ${ }^{87} \mathrm{Sr} /{ }^{86} \mathrm{Sr}$ of NIST 987 to be 0.710256 . To investigate the variation of strontium isotope composition in the method, the compositions of strontium isotope in a standard solution before UA-DLPME and after UA-DLPME under the optimum condition were measured to 0.711052(28) and 0.711076(43), which demonstrated that there was no fractionation of strontium isotope occur in UA-DLPME. Under the same condition, the variations of strontium isotope composition in three samples were given in Table-4. The variation of strontium isotopic composition in these samples was the same as that reported by Sivaji et al. ${ }^{17}$ and Wang et $a l^{18}$, which may be combined with the rock weathering, or the interaction between the environmental samples, such as soil, rainwater etc.
TABLE-4

STRONTIUM ISOTOPIC COMPOSITION IN REAL SAMPLE

\begin{tabular}{cc}
\hline Water samples & Measured value of Sr isotope \\
\hline Tap water & $0.710360(45)$ \\
River water & $0.711339(76)$ \\
Wastewater & $0.711674(66)$ \\
Underground water & $0.709112(65)$ \\
\hline
\end{tabular}

\section{Conclusion}

In the present work, a new method of microextraction as ultrasonic-assisted dispersive liquid phase microextration with low-volume toxic solvent was described, which proposed the extraction of $\mathrm{Sr}(\mathrm{II})$ in water samples and combined with ICOOES. The linear range of the method is sufficient for the determination of $\mathrm{Sr}(\mathrm{II})$. The method can be successfully applied for the measurement of strontium and its isotopic composition in environmental samples.

\section{ACKNOWLEDGEMENTS}

This study was financially supported by the Program for Natural Science Foundation of China (No. 41072138, No. 41172160) and the Program for Natural Science Foundation of Shandong Province, China (No. ZR2010DM002) and the Program for the Western Light Foundation of the Chinese Academy of Sciences (2010) .

\section{REFERENCES}

1. R.A. Bentley, J. Archaeol. Method Theo., 13, 135 (2006).

2. K.M. Frei and R. Frei, Appl. Geochem., 26, 326 (2011).

3. P. Degryse, D. De Muynck, S. Delporte, S. Boyen, L. Jadoul, J. De Winne, T. Ivaneanu and F. Vanhaecke, Anal. Methods, 4, 2674 (2012).

4. M. Kazempour, E. Sundstrom and V. Alvarado, Soc. Petroleum Eng., 92, 216 (2012).

5. E. Beaulieu, Y. Goddéris, D. Labat, C. Roelandt, D. Calmels and J. Gaillardet, Chem. Geol., 289, 114 (2011).

6. D. Li, G.A. Shields-Zhou, H.-F. Ling and M. Thirlwall, Chem. Geol., 290, 133 (2011).

7. H.C. Chao, C.F. You, H.C. Liu and C.H. Chung, Geophys. Res. Abstr., 14, 4056 (2012).

8. X.L. Liu, C.Q. Liu, S.L. Li and X.D. Li, Chin. J. Ecol., 29, 978 (2010).

9. K.J. Knudson, T.D. Price, J.E. Buikstra and D.E. Blom, Archaeometry, 46, 5 (2004).

10. P.-P. Tang, Z.-F. Luo, J.-B. Cai and Q.-D. Su, Chin. J. Anal. Chem., 38, 999 (2010).

11. F.L. Fan, F.Y. Fan and Z. Qin, IMP \& HIRFL Annual Report, 81 (2010).

12. Z. Valentová, P. Vanura and E. Makrlík, J. Radioanal. Nucl. Chem., 267, 471 (2006).

13. P. Nový, P. Vanura and E. Makrlík, J. Radioanal. Nucl. Chem., 231, 65 (1998).

14. R.S. Zhao, X. Wang, J. Sun, S.S. Wang, J.P. Yuan and X.K. Wang, Anal. Bioanal. Chem., 397, 1627 (2010).

15. G. Khayatian and S. Hassanpoor, J. Chin. Chem. Soc., 59, 659 (2012).

16. M. Mohamadi and A. Mostafavi, Talanta, 81, 309 (2010).

17. P. Sivaji, C.Q. Liu, Q.L. Wang and Z.L. Wangm Earth Environ., 37, 333 (2009).

18. B. Wang, X.Q. Li, H.L. Yuan, H. Zhou and Y.L. Zhao, Environ. Chem., 28, 876 (2009). 